\title{
EVALUATION OF SOME CHEMICAL-INJECTION EQUIPMENT WITH PRESSURIZED IRRIGATION SYSTEMS
}

\author{
A. M. El Lithy ${ }^{(*)}$
}

\section{ABSTRACT}

The aim of this research is to evaluate hydraulic performance of prevailing chemical injection equipment used with pressurized irrigation systems including; (1) By-pass pressure differential tank, (2) With suction pipe of irrigation pump, (3) Separate electric centrifugal pump, and (4) Venturi, to help in selecting an appropriate chemical injector according to field and operating conditions. The main results in this study can be summarized in the following:

*The average of injection rates were: 190, 380, 1000, and 1175 for venturi, by-pass differential tank, with suction pipe of irrigation pump, and separate electric centrifugal pump respectively, at pressure drop or irrigation pressure of $100 \mathrm{kPa}$.

* The average uniformity of injection rate ranged from 94.8 to $99 \%$ during fertigation time for prevailing equipment under study.

* Economical verification of the feasibility of using chemical injectors is discussed according to different field conditions.

\section{INTRODUCTION}

election of proper chemical injection technique in pressurized irrigation systems is the farmer/ engineer key to higher yields and healthier crops. Also the choice of suitable fertilizers is also very important and based on several factors like nutrient form, purity, solubility, and cost.

It is very important to select a fertilizer injection method that best suits irrigation system and crop to be grown, whereas each fertilizer or chemical injector is designed for a specific pressure and flow range. So care must be taken in selecting a fertigation system that suits farm condition and requirenment. Caleder and Bert (2007).

(*) Assoc. Prof., Ag. Eng. Dept., Col. of Ag., Al -Azhar U., Assiut. 
Awady in 1992 listed five methods for fertigation devices: 1- with positive-pressure pump, 2- with venture, 3- differential-pressure tank, 4using the main irrigation pump to withdraw fertilizer solution from an open tank, and 5- hydraulically-actuated pump, the method differ according to: rate of application, energy consumptive, and price, but they all must uniformly apply fertilizer over the irrigation area.

Janos (1995) stated that to inject the fertilizer solution into the irrigation system four different fertigators can be used: venturi, by-pass flow tank, pressure differential system or injection pump. The general advantages of the injection pump system are: the high degree of control of dosage and timing of chemical application, centralized and sophisticated control, portability, no serious head loss in the system, labour-saving and relatively cheap in operation. With this method the solution is normally pumped from an open unpressurized tank, and the choice of type of pump used is dependent on the power source. The pump may be driven by water flow, by an internal combustion engine, by an electric motor or by a tractor power take-off.

Kranz et al. (1996) found that chemical injection devices (piston, diaphragm, and venturi type injection) with the same model number do not deliver identical calibration curves, outlet pressure significantly affects the slope of the calibration curve, and the manufacturer calibration curve may not be appropriate for the operating conditions experienced with most center pivot installations, for a series of outlet pressures ranging from 207 to $690 \mathrm{kPa}$ (30 to $100 \mathrm{psi}$ ).

Coates et al. (2012) reported that all fertigation techniques performed well, with fertilizer distribution uniformities between 0.88 and 0.96 . Selection of the optimum site-specific fertigation strategy will depend on crop needs, scheduling limitations, and system design parameters such as emitter type, fluid travel time, and slope.

Bakeer (2002) (a and b) and Badr et al. (2006) recommended avoiding fertigation devices that depend on the differential pressure between the inlet and outlet as much as possible and using hydraulically actuated chemigator for saving water, energy and money. 
On the middle of 90s, some of the farmers injected the fertilizer through the irrigation system by the suction pipe of the irrigation water pumps, many of the farmers are used to it nowadays (39.4\%). EL Zuraiqi S. et al. (2004).

Jiusheng et al. (2007) stated that both manufacturing variability of emitters and injector types had a very significant effect on the uniformity of fertilizer applied, while the uniformity of water application was mainly dependent on emitter type.

Kassem and AL-Suker (2009) reported that fertigation using injection pump records efficient and highest values of water and nitrogen use efficiency for wheat and barley crops, among different methods used, according to the experimental results during 2006/2007 and 2007/2008 seasons in experimental farm conditions of, Al-Qassim University.

The aims of this research are:

1. Study the affecting factors on use of chemical injection equipment for the maximum operating efficiency according to field conditions.

2. Evaluate the available injection equipment used in irrigation system for proper operation and maintenance, and

3. Conduct field experiments to identify the operating and hydraulic criteria for chemical injection at different field conditions.

\section{MATERIALS AND METHODS}

Field experiments were conducted in a private farms in "El Sharqia " governorate that included wide variety of parameters and field conditions as presented in table 1 to collect hydraulic and engineering data, that help to select proper injection equipment according to field conditions.

\section{Components of the prevailing chemical injection equipment (CIU).}

The components and required data in addition to drawings of chemical injection equipment used in the study, are presented in table 2 and fig. 1 (a,b,c and d) as follows:

(1) By-pass differential tank. (Fig.1 a).

(2) With suction pipe of irrigation pump. (Fig.1 b).

(3) Separate electric centrifugal pump. (Fig.1 c), and

(4) Venturi (Fig.1 d). 


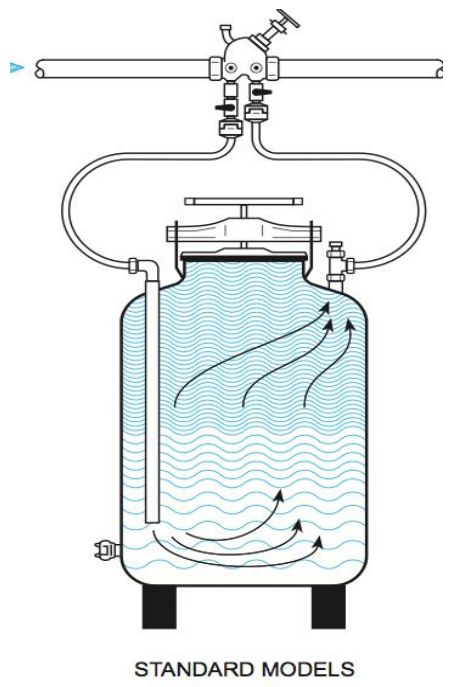

(a) Bypass differential tank.

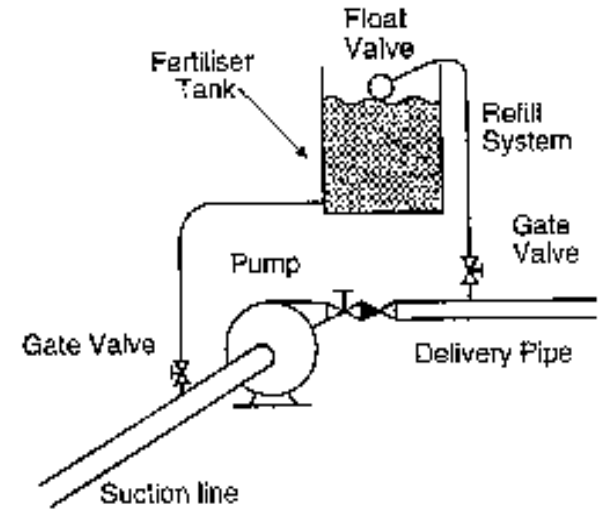

(b) Fertilizer injection with suction pipe of irrigation.

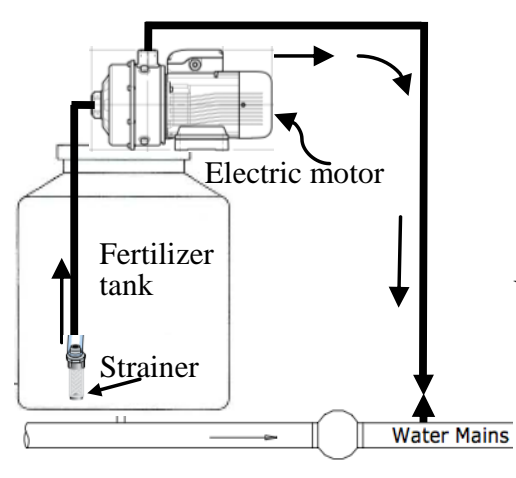

(c) Separate electric centrifugal injection pump $(1.13 \mathrm{~kW})$.

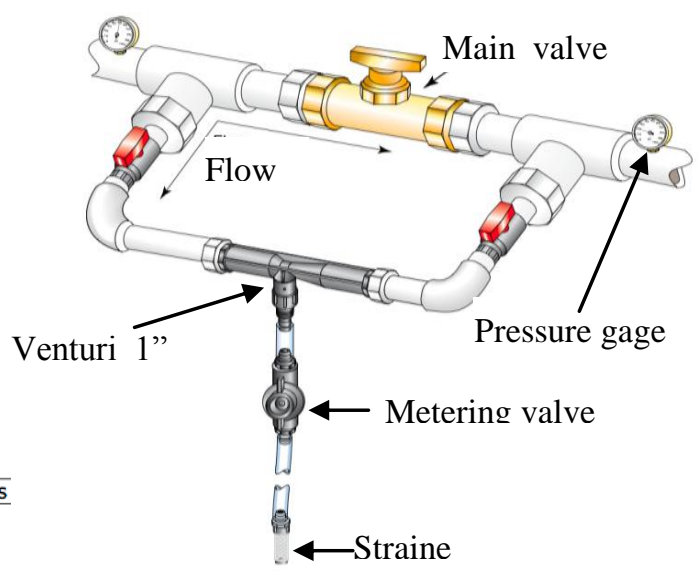

(d) Venturi 1".

Fig. 1. Chemical injection equipment. 
Table 1: The actual farm condition under investigation including engineering and hydraulic criteria of irrigation system

\begin{tabular}{|c|c|c|c|c|}
\hline \multirow{2}{*}{ Farm conditions } & \multicolumn{4}{|c|}{ Farm under case study } \\
\hline & $\mathbf{A}$ & $\mathbf{B}$ & $\mathrm{C}$ & $\overline{\mathbf{D}}$ \\
\hline 1-Location & Belbeis* & Adleia* & Orabi* & Adleia* \\
\hline 2-Area,fed. & 70 & 8 & 7 & 10 \\
\hline 3-Irrigation system & \multicolumn{4}{|c|}{ Trickle irrigation systems } \\
\hline 4- Water source & Well & $\begin{array}{l}\text { Ismailia } \\
\text { canal }\end{array}$ & $\begin{array}{c}\text { Ismailia } \\
\text { canal \# }\end{array}$ & $\begin{array}{l}\text { Under- grounc } \\
\text { reservoir }\end{array}$ \\
\hline 5- Crop & Mango & Orchard & Mango & Pomegranate \\
\hline 6-Tree spacing & $4 \times 2$ & $6 \times 3$ & $3 \times 1.75$ & $3 \times 3.5$ \\
\hline $\begin{array}{l}7 \text { - Distance from } \\
\text { water source and } \\
\text { pump unit, } m \text {. }\end{array}$ & 600 & 1600 & 400 & 150 \\
\hline $\begin{array}{l}\text { 8- Pump discharge } \\
\mathrm{m}^{3} / \mathrm{h} \text {. }\end{array}$ & 120 & 130 & 50 & 70 \\
\hline $\begin{array}{l}\text { 9- System pressure, } \\
\text { bar. (kPa.). }\end{array}$ & $3(300)$ & $1.5(150)$ & $3.5(350)$ & $2.5(250)$ \\
\hline 10-Irrigation time ,h. & 10 & 2 & 10 & $2-6$ \\
\hline $\begin{array}{l}\text { 11- Average of } \\
\text { chemical } \\
\text { injection/irrigation } \\
\text { time, } \mathrm{m}^{3} / \mathrm{h} \text {. }\end{array}$ & 1.0 & $0.2-0.5$ & $0.2-1.0$ & $0.5-1.0$ \\
\hline 12. Power source & Electricity & Hydraulic & Electricity & Diesel \\
\hline $\begin{array}{l}\text { 13. Injection } \\
\text { equipment tested }\end{array}$ & $\begin{array}{c}\text { Separate } \\
\text { electric } \\
\text { centrifugal } \\
\text { injection } \\
\text { pump (1.13 } \\
\text { kW). } \\
\text { (Fig.1 c). }\end{array}$ & $\begin{array}{l}\text { Venturi 1" } \\
\text { (Fig.1 d). }\end{array}$ & $\begin{array}{c}\text { With suction } \\
\text { pipe of } \\
\text { irrigation } \\
\text { pump. } \\
\text { (Fig.1 b). }\end{array}$ & $\begin{array}{c}\text { By-pass } \\
\text { differential } \\
\text { tank. (Fig.1 } \\
\text { a). }\end{array}$ \\
\hline
\end{tabular}

* بلبيس ، العادلية ، عرابى ، العادلية على الترتيب. \# ق قناة الاسماعيلية. 
Table2: Hydraulic and engineering specs for chemical injection equipment.

\begin{tabular}{|c|c|c|c|c|}
\hline \multirow[b]{2}{*}{$\begin{array}{c}\text { Injector } \\
\text { specifications }\end{array}$} & \multicolumn{4}{|c|}{ CHEMICAL INJECTION EQUIPMENT } \\
\hline & $\begin{array}{l}\text { (1) } \\
\text { By-pass } \\
\text { differential } \\
\text { tank. (Fig.1 a). }\end{array}$ & $\begin{array}{l}\text { (2) } \\
\text { With suction } \\
\text { pipe of } \\
\text { irrigation } \\
\text { pump. } \\
\text { (Fig.1 b). }\end{array}$ & $\begin{array}{l}\text { (3) } \\
\text { Separate } \\
\text { electric } \\
\text { centrifugal } \\
\text { injection pump } \\
(1.13 \mathrm{~kW}) . \\
(\text { Fig.1 c). }\end{array}$ & $\begin{array}{l}\text { (4) } \\
\text { Venturi 1" } \\
\text { (Fig.1 d). }\end{array}$ \\
\hline $\begin{array}{l}\text { Operating } \\
\text { pressure range, } \\
\text { (kPa.) }\end{array}$ & 200-800 & $200-400$ & $200-400$ & $200-400$ \\
\hline $\begin{array}{l}\text { Injection rate, } \\
\mathrm{m}^{3} / \mathbf{h} \text {. }\end{array}$ & $0.120-0.350$ & $0.1-4$ & $0.1-1.8$ & 0.1-0.4 \\
\hline $\begin{array}{l}\text { Required power } \\
\text { source }\end{array}$ & Hydraulic & Electric/diesel & Electric & Hydraulic \\
\hline $\begin{array}{l}\text { Connection, } \\
\text { Inch ("). }\end{array}$ & $3 / 4 "$ & $1 "$ & $1.1 / 4 " / 1 \%$ & $1 ”$ \\
\hline Total mass, kg. & 45 & 0.5 & 18 & 0.75 \\
\hline $\begin{array}{l}\text { Tank capacity, } \\
\mathbf{m}^{3}\end{array}$ & 0.12 & 1 & 1 & $0.2-1$ \\
\hline $\begin{array}{l}\text { Construction } \\
\text { material }\end{array}$ & steel & $\begin{array}{c}\text { Chemical- } \\
\text { resistant } \\
\text { plastics }\end{array}$ & Stainless steel & $\begin{array}{c}\text { Chemical- } \\
\text { resistant } \\
\text { plastics } \\
\end{array}$ \\
\hline
\end{tabular}

\section{Chemical injection rate:}

The chemical injection rate was measured for equipment (b, c, and d) by recording chemical decreasing level in chemical tank with time using measuring tape with accuracy of $1 \mathrm{~mm}$. and stop watch. Whereas for the chemical injection unit (a) EC meter (rang from 0 to $3 \mathrm{mmhos} / \mathrm{cm}$ with accuracy of $0.01 \mathrm{mmhos} / \mathrm{cm}( \pm 2 \%)$ ), was used to record EC reading of irrigation water during injection time till reaching to the same reading of irrigation water EC recorded before starting of chemicals injection from chemical tank of known capacity. (That means the chemical in the chemical tank was ejected to the irrigation system). 


\section{Irrigation pressure and pressure drop:}

Pressure gages ranging from 0 - $600 \mathrm{kPa}$ with an accuracy of $10 \mathrm{kPa}$ were used to measure the working pressure of the irrigation system with separate electric centrifugal injection pump and with suction pipe of irrigation pump equipment. The pressure drop was measured using two pressure gages connected before and after chemical injector equipment for venturi and by-pass pressure differential tank.

\section{Injection uniformity.}

The uniformity of injection rate during injection time was determined using Cheristiansen coefficient "CU" Christiansen (1942)

$$
\mathrm{CU}=(1-|\sigma|) .100
$$

where :

CU: coefficient of uniformity

$|\sigma|$ : absolute mean deviation of injection rate on injection time.

\section{Correlation between measured and calculated data.}

The following equation was used to calculate correlation between measured and calculated data. (Nigm, 1993 in Arabic).

$$
\mathrm{R}^{2}=\frac{\sum(x-\bar{x})(y-\bar{y})}{n \cdot \sigma_{x} \cdot \sigma_{y}}
$$

Where: $\mathrm{R}^{2}=$ correlation between two groups of data, $\mathrm{x}=$ data number in the first group, $\bar{x}, \bar{y}=$ average, $y=$ data number in the second group $\sigma \mathrm{x}, \sigma \mathrm{y}=$ standard deviation, and $\mathrm{n}=$ number of data.

\section{RESULTS AND DISCUSSION}

\section{Hydraulic characteristics of chemical injection equipment (CIE).}

Fig. 2 shows the relation between injection rate and pressure drop for different injectors tested with irrigation system, under the same operating conditions. It is clear that an increasing of injection rates was recorded for venturi (from 90 to $395 \mathrm{~L} / \mathrm{h}$ ) and by-pass differential tank (from 160 to $620 \mathrm{~L} / \mathrm{h}$ ) by increasing of pressure drop from 40 to $140 \mathrm{kPa}$. Whereas injection rate for separate pump decreased from 1280 to $1030 \mathrm{~L} / \mathrm{h}$. by 
increasing of irrigation pressure from 40 to $140 \mathrm{kPa}$., due to pump characteristics, as presented in table 2 used to inject chemicals from chemical tank to irrigation system. Discharge decreasing by increasing the resistance to injection rate is caused by increasing of irrigation system pressure. It is clear also that using of suction pump pipe to inject chemical with irrigation system was not affected by irrigation pressure increasing from 40 to $140 \mathrm{kPa}$., and it recorded a constant injection rate of $1000 \mathrm{~L} / \mathrm{h}$ due to the great difference between maximum chemical injection rate (1 $\left.\mathrm{m}^{3} / \mathrm{h}\right)$ and irrigation pump discharge rate $\left(50 \mathrm{~m}^{3} / \mathrm{h}\right)$ as presented in table 1. That gave more stability for this technique of chemical injection against wide range of irrigation system pressure changes.

\section{Injection rate during injection time.}

Fig. 3 reflects the effect of operating time on injector rate for available chemical injection equipment. The average of injection rate for venturi, with suction pipe of irrigation pump, and separate electric centrifugal pump, were 190, 1000, and 1175 respectively.

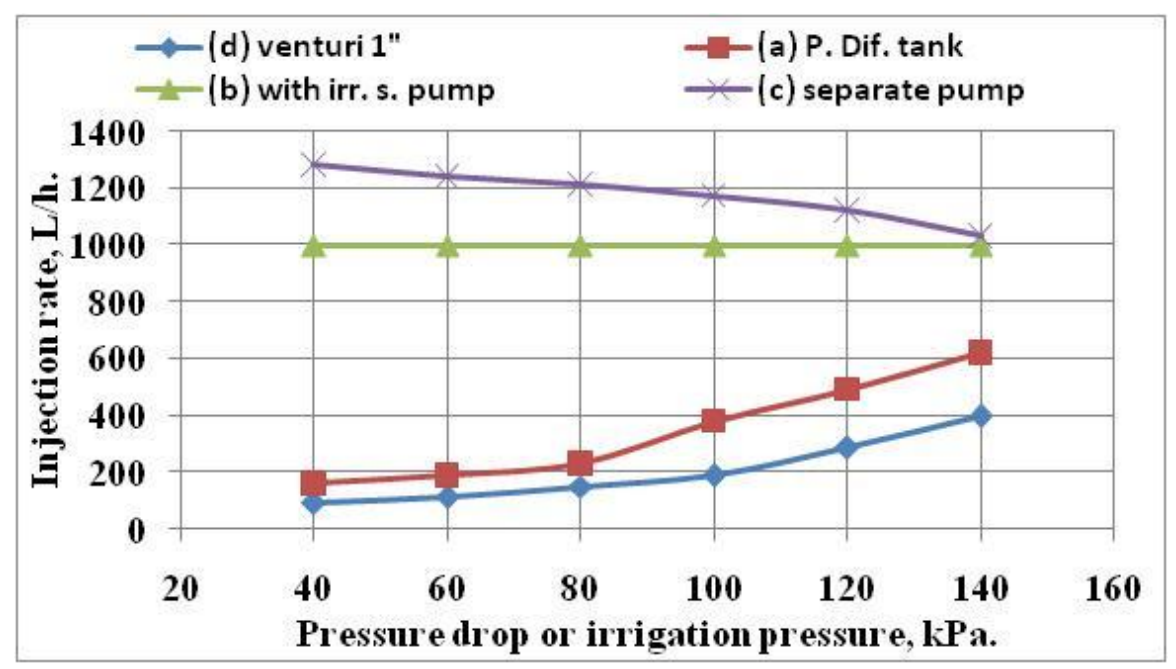

Fig. 2 : Performance of chemical injectors. 


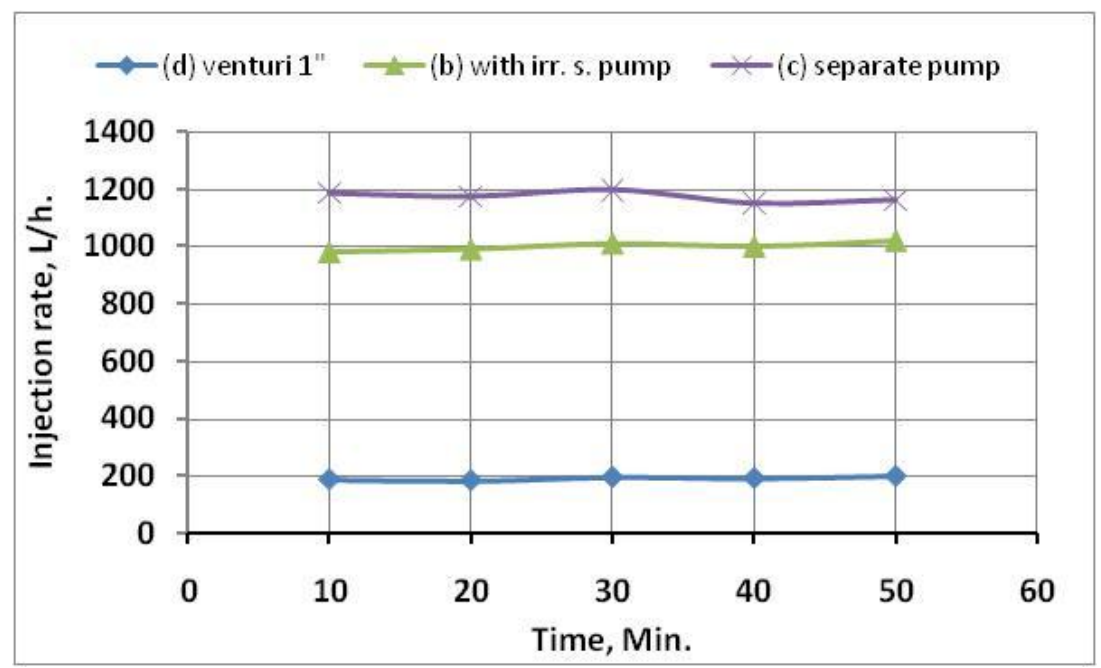

Fig. 3: Injection rate for different chemical injection equipment during injection time at pressure drop of $100 \mathrm{kPa}$.

\section{Injection rate uniformity during injection time.}

Fig. 4 shows the effect of pressure drop or irrigation system pressure on injection rate uniformity during the injection time for different equipment used for chemical injection in irrigation systems. The highest value of injection rate uniformity ranged from 98.8 to $99 \%$ recorded with using suction pipe of irrigation pump to inject chemical in irrigation system. Whereas, by increasing irrigation system pressure from 40 to $120 \mathrm{kPa}$, the uniformity of injection rate decreased from 98.8 to $95.2 \%$ for chemical injection using separate pump due to increasing the resistance of chemical injection by increasing irrigation system pressure. Meanwhile, there ware no significant effects of pressure drop or irrigation system pressure increasing on the uniformity of injection rate during injection time for other injection equipment according to experiment conditions.

\section{Hydraulic characteristics of designed and imported types of chemical injectors.}

The relation between injection rate and pressure drop or irrigation system pressure for chemical injector equipment under study is expressed in three equations, shown in fig. 5 for each injector with acceptable correlation between measured and calculated data (84-94\%). 


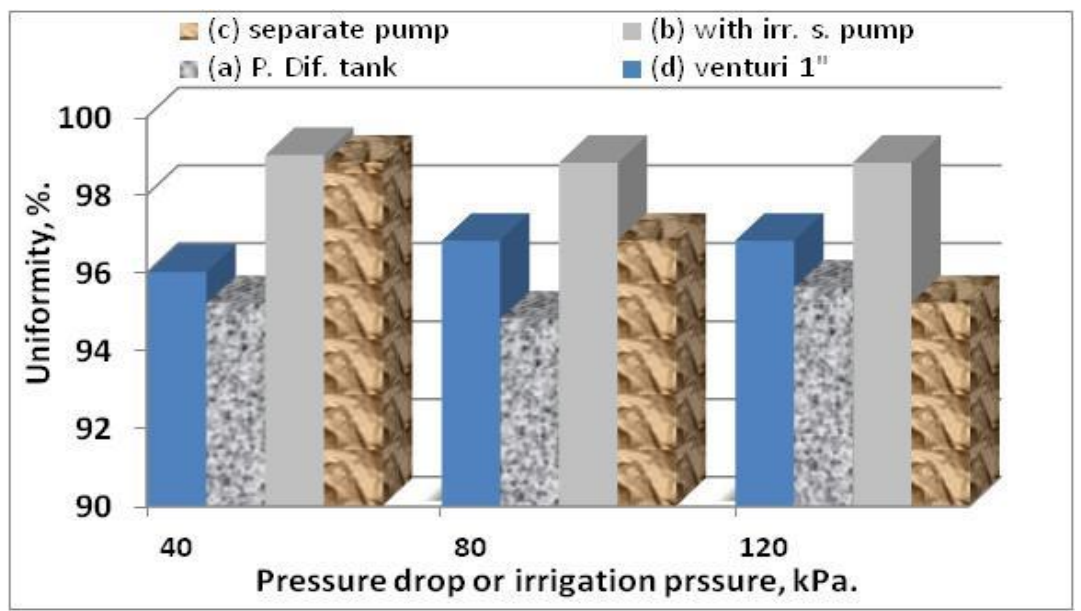

Fig. 4: Effect of pressure drop or irrigation pressure on injection rate uniformity for different chemical injection equipment.

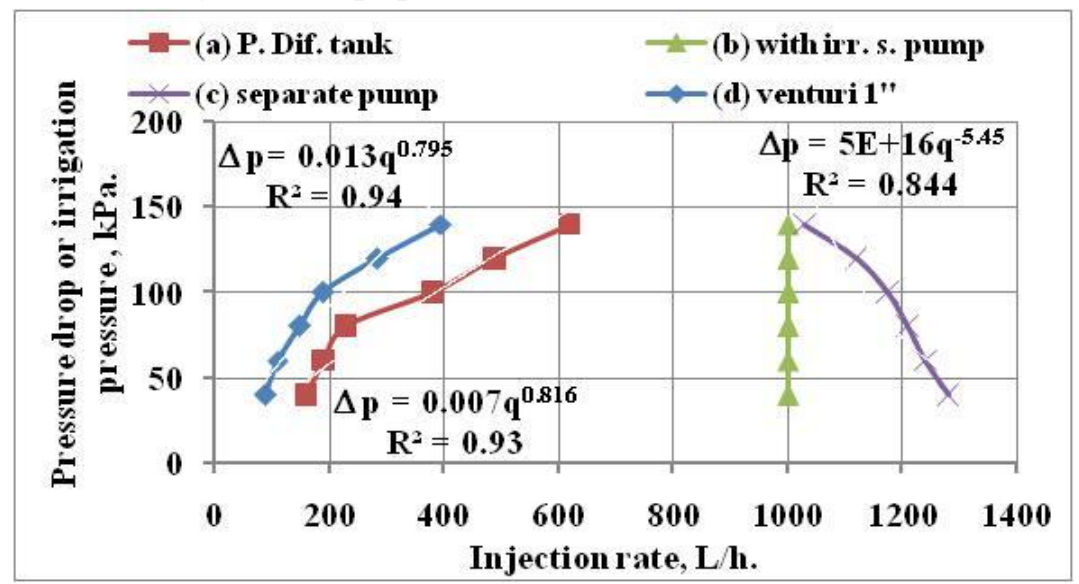

Fig. 5: Hydraulic characteristics of chemical injector equipment.

\section{Cost comparison.}

Table 3 shows the total initial cost for different prevailing equipment used in chemical injection in irrigation system under study were 450, 350, 3200 and 550 L.E. for (a) Pressure differential Tank, (b) with irrigation suction pump, (c) using separate pump, and (d) venturi 1" respectively. As a result of using suction pipe of irrigation pump to inject chemical in irrigation system, a saving of about $29 \%$ and $57 \%$ was obtained compared with using pressure differential tank or venturi for chemical injection in 
irrigation line. Meanwhile, using separate pump record the highest cost among other equipment.

Table 3: Cost details and comparison between designed and imported chemical injectors.

\begin{tabular}{|l|l|l|c|c|}
\hline \multirow{2}{*}{$*$ Material } & \multicolumn{4}{|c|}{ Cost, L.E.* } \\
\cline { 2 - 5 } & $\begin{array}{l}\text { (a)P. } \\
\text { Dif. } \\
\text { Tank }\end{array}$ & $\begin{array}{l}\text { (b) } \\
\text { with } \\
\text { irr. s. } \\
\text { pump }\end{array}$ & $\begin{array}{l}\text { (c) } \\
\text { separate } \\
\text { pump }\end{array}$ & $\begin{array}{l}\text { (d) } \\
\text { venturi } \\
1 "\end{array}$ \\
\hline Injector & $* * 350$ & 0 & 0 & 450 \\
\hline Engine with pump & 0 & 0 & 2650 & 0 \\
\hline $\begin{array}{l}\text { Valves and } \\
\text { connectors }\end{array}$ & 100 & 100 & 150 & 150 \\
\hline Chassis for fixing & 0 & 0 & 150 & 0 \\
\hline Fertilizer tank & 0 & 250 & 250 & 250 \\
\hline Total & 450 & 350 & 3200 & 550 \\
\hline
\end{tabular}

*Material cost according to local market price, 2012.

** Local fabricated chemical fertilizer tank price with capacity of 120

liter according to local market price, 2012.

\section{SUMMARY AND CONCLUSION}

An evaluation of prevailing chemical injector equipment was carried out to help in selecting the proper chemical injector according to field and operating conditions.

Chemical injection equipment under study were: (a) pressure differential tank, (b) with irrigation suction pump, (c) using separate pump, and (d) venturi 1", .

The main results in this study can be summarized in the following:

*The average injection rate was recorded for venturi, by-pass differential tank, with suction pipe of irrigation pump, and separate electric centrifugal pump: were $190,380,1000$, and $1175 \mathrm{~L} / \mathrm{h}$. respectively at differential pressure drop of $100 \mathrm{kPa}$.

* Three equations, derived from curve fitting of characteristics curve, can be used to get the injection pressure required for injected flow rate with an acceptable correlation of $94 \%$, for venturi (Eq. 1), and 94, 84\% for (differential pressure tank and separate pump), (Eq. 2 and 3) respectively as following equations:

$$
\Delta \mathrm{P}=0.0139 \mathrm{q}^{0.795}
$$




$$
P=5 E+169 q^{-5.45}
$$

Where: "q" is the rate of injection, $\mathrm{L} / \mathrm{h}$, " $\Delta \mathrm{P}$ " pressure drop, $\mathrm{kPa}$. "P" irrigation pressure, $\mathrm{kPa}$.

*The total initial costs for different available equipment used for chemical injection in irrigation system under study were 450, 350, 3200 and 550 L.E. for (a) pressure differential tank, (b) with irrigation suction pump, (c) using separate pump, and (d) venturi 1" respectively.

*A saving of about $29 \%$ and $57 \%$ was obtained in injection rate with using with irrigation suction pump technique compared with using pressure differential tank or venturi for chemical injection in pressurized irrigation system.

*The highest value of injection rate uniformity ranging from 98.8 to $99 \%$ was recorded with using suction pipe of irrigation pump, whereas the lowest value of injection rate uniformity ranging from $94.8 \%$ to $95.6 \%$ was recorded with using pressure differential tank to inject chemical in irrigation system.

\section{REFERENCES}

Awady, M. N., 1992, Irrigation by trickling methods, Amer U. in Cairo, Desert Dev. Center, Ir. Traing. Prog.: 50 P. (In Arabic).

Badr, A. A., Ebabi, F. G., and ELtomy, E. O., 2006, Fertigation methods effects on water and fertilizer uniformity in drip irrigation, Misr J. Ag. Eng., 23(1): 122 - 136.

Bakeer, G. A., 2002 a, Chemical injection effect on deep whell-pump in drip irrigation, Misr J. Ag. Eng., 19(4): 821- 840.

Bakeer, G. A 2002 b, Fertigation methods effects on water and fertilizer uniformity in drip irrigation, Misr J. Ag. Eng., 19(4): 821- 840.

Caleder, T. and Bert, J., 2007, Selection of fertigation equipement, http://www.agric.wa.gov.au/objtwr/imported_assets/cotent/hort/eng/ f03501.pdf (Accessed on October 2009).

Christiansen, J.E., 1942, Irrigation by Sprinkling. California Agriculture Experiment Station Bulletin, No. 670.

Coates, R. W., Sahoo, P. K., Schwankl, L. J. and Delwiche, M. J., 2012, Fertigation techniques for use with multiple hydrazones in simultaneous operation. Precision 13(2): 219-235. 
EL Zuraiqi, S., Rusan, M. J., and AL Qawasmi, W., 2004, Fertigation in Jordan, IPI Regional Workshop on Potassium and Fertigation development in West Asia and North Africa; Rabat, Morocco: 2428.

Janos, L. 1995, Application of chemicals through irrigation systems. ICID J. 45 No. 2: 125-146.

Jiusheng, L., Yibin, M., and Bei, L., 2007, Field evaluation of fertigation uniformity as affected by injector type and manufacturing variability of emitters, Ir. Sc., Volume 25 (2): 117-125.

Kassem, M. A. and AL-Suker, A., 2009, Effect of fertigation methods on productivity and nitrogen use efficiency for wheat and barly crops, Misr J. Ag. Eng., 26(2): 866- 885.

Kranz, W. L., Eisenhauer, D. E., Parkhurst, A. M., 1996, Calibration accuracy of chemical injection devices, Applied Engineering in Agriculture. 12(2): 189-196.

Negm, A. M., 1993, Descriptive and analytical statistics by using ready made software, P. 199.(In Arabic).

الملخص العربح

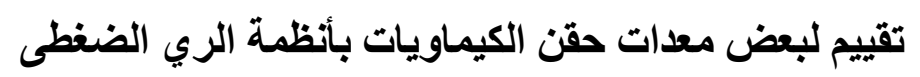

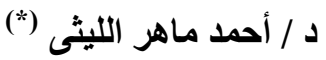

يهدف البحث الى تقييم الأداء الهيدرولى لمعدات حقن الكيماويات الزراعية شائعة الاستخدام

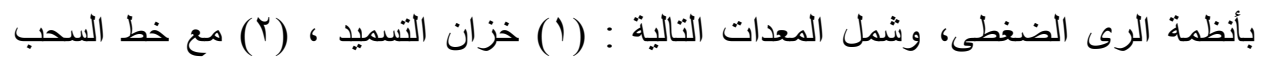

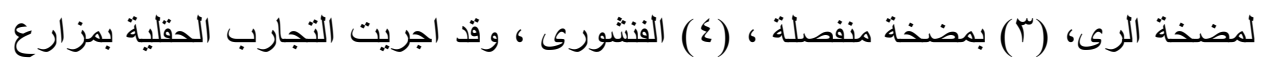

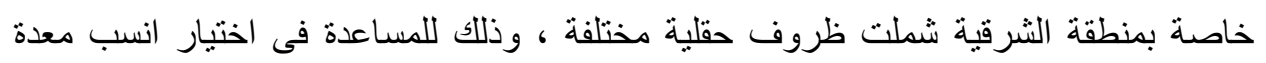

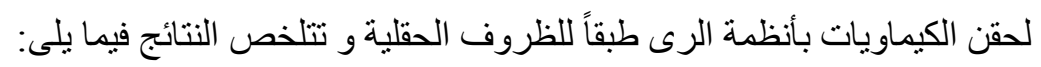

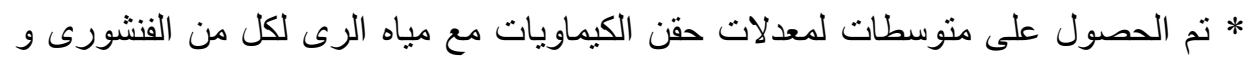

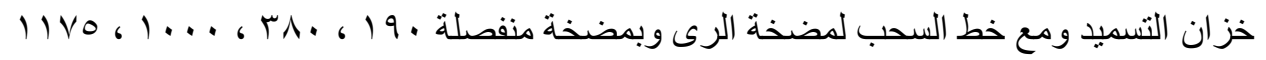

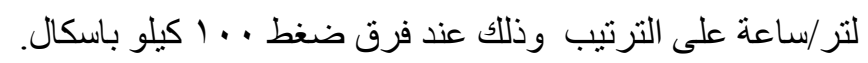

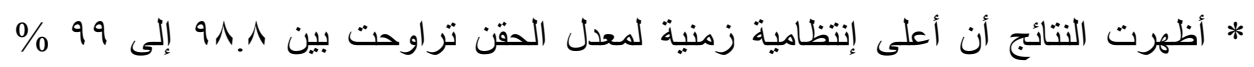

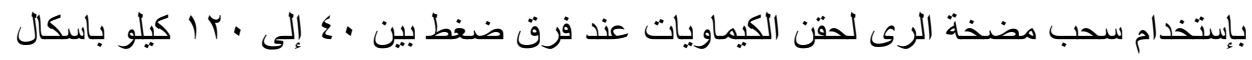

$$
\text { (*) أستاذ الهندسة الزراعية المساعد_ك. الزراعة_ ج. الأزهر- فرع أسيوط. }
$$


على الترتيب ، بينما أقل قيمة لانتظام معدل الحقن أثناء زمن الحقن تراوحت بين ^.؟؟ إلى بلى 7 \% 90 \% بإستخدام خزان التسميد عند نفس فرق الضغط

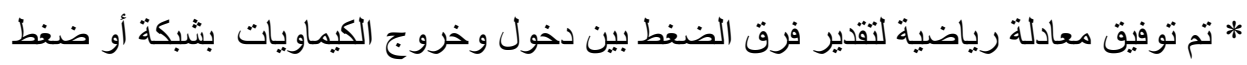

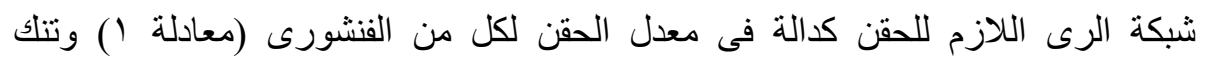

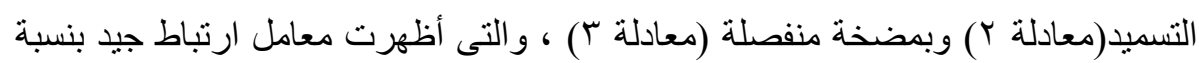

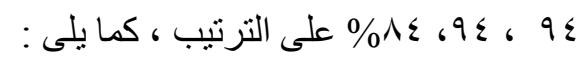

$$
\begin{aligned}
& \Delta \mathrm{P}=0.0139 \mathrm{q}^{0.795} \\
& \text { (1) } \Delta \mathrm{P}=0.0079 \mathrm{q}^{0.816} \\
& \mathrm{P}=5 \mathrm{E}+169 \mathrm{q}^{-5.45}
\end{aligned}
$$

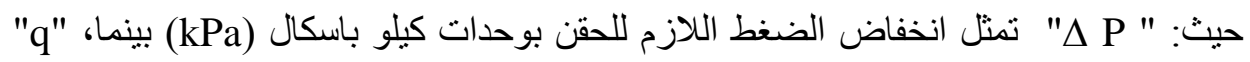
تمثل معدل الحقن بوحدات لتر /ساعة.

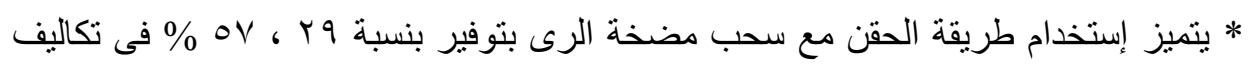

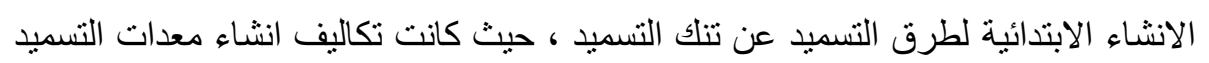

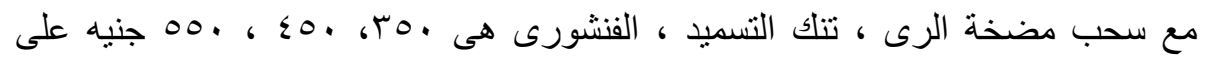

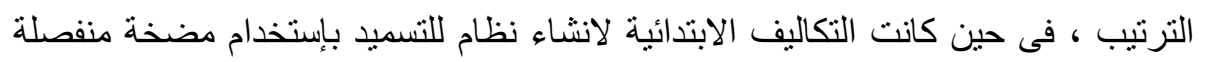

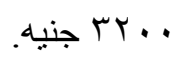

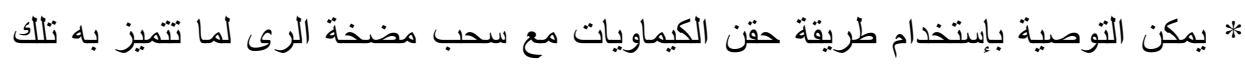

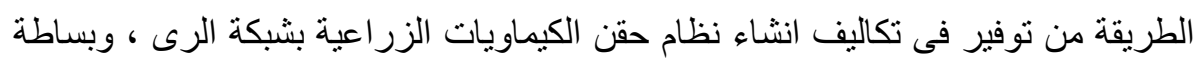

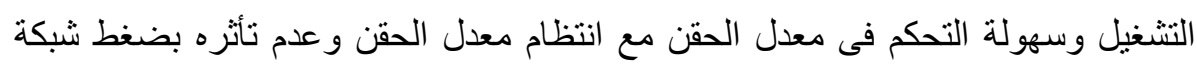

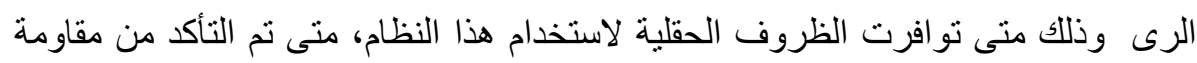
مو اد انثاء المضخة الداخلية للكيماويات المستخدمة وظو اهر التكهف (Cavitation). 